\title{
The Role of Intergenerational Transfers in Aggregate Capital Accumulation
}

\section{Laurence J. Kotlikoff}

Yale University

\section{Lawrence H. Summers}

Massachusetts Institute of Technology

\begin{abstract}
This paper uses historical U.S. data to directly estimate the contribution of intergenerational transfers to aggregate capital accumulation. The evidence presented indicates that intergenerational transfers account for the vast majority of aggregate U.S. capital formation; only a negligible fraction of actual capital accumulation can be traced to life-cycle or "hump" savings. A major difference between this study and previous investigations of this issue is the use of more accurate longitudinal age-earnings and age-consumption profiles. These profiles are simply too flat to generate substantial life-cycle savings. This paper suggests the importance of and need for substantially greater research and data collection on intergenerational transfers. Life-cycle models of savings that emphasize savings for retirement as the dominant form of capital accumulation should give way to models that illuminate the determinants of intergenerational transfers.
\end{abstract}

During the past quarter century, the life-cycle hypothesis (Modigliani and Brumberg 1954; Ando and Modigliani 1963) has emerged

We are indebted to R. Barro, M. Boskin, G. Chamberlain, R. Clower, M. Darby, S. Engerman, M. Feldstein, V. Fuchs, R. Gordon, E. Leamer, P. Menchik, J. Skinner, and F. Welch for enlightening discussions. We thank the Foundation for Research in Economic Education; the Department of Health, Education, and Welfare; and the National Bureau of Economic Research for providing research support. All views expressed here are solely those of the authors. 
as the principal theory of aggregate saving in the American economy. It has stimulated a vast quantity of research testing and exploring its implications. Despite this effort, the importance of lifetime consumption smoothing to the process of capital accumulation remains unresolved. ${ }^{1}$ This paper presents evidence that the pure life-cycle component of aggregate U.S. savings is very small. American capital accumulation results primarily from intergenerational transfers. Distinguishing the roles of life-cycle savings and intergenerational transfers in the capital accumulation process is crucial to a number of economic issues. Economic models that incorporate intergenerational transfers can generate strikingly different results for a number of major economic questions, including the burden of the national debt, the impact of social security on savings, the incidence of taxation, the perpetuation of the inequality of wealth, and the optimal structuring of taxes to promote economic growth (see, e.g., Diamond 1970; Atkinson 1971; Feldstein 1974; Oulton 1976; Calvo, Kotlikoff, and Rodríguez 1979).

This paper has two objectives. The first is simply to answer an accounting question, namely, can life-cycle savings alone account for the U.S. capital stock? The second goal is to answer an economic question: If, ceteris paribus, there were no intergenerational transfers, how large would the U.S. capital stock be? That is, if all such transfers were taxed in a confiscatory way, by how much would capital accumulation be reduced? We find that life-cycle savings cannot explain the capital stock in an accounting sense and that in the absence of intergenerational transfers the U.S. capital stock would be substantially smaller.

Our findings are based on a new methodological approach. ${ }^{2}$ In particular, a variety of historical U.S. data detailing population, labor earnings, consumption, and government taxes and transfers are used to directly estimate the shapes of historic age-earnings and ageconsumption profiles. These profiles are combined with data on rates of return to calculate a stock of life-cycle wealth. This stock of lifecycle wealth is compared with aggregate wealth holdings in the United States. If there were no intergenerational transfers, the stock of life-cycle wealth would exactly equal total U.S. wealth. When intergenerational transfers occur, these two stocks differ by an amount equal to the stock of net received transfers. Hence, comparing total wealth with life-cycle wealth indicates whether the life-cycle model

\footnotetext{
${ }^{1}$ Tobin (1967) and Boskin (1978) argue that life-cycle savings are the predominant form of savings in the United States. White (1978) and Darby (1979) argue otherwise. Tobin and Dalde (1971) provide a somewhat intermediate view.

${ }^{2}$ Our methodological approach was influenced by and is similar to those of Brittain (1978) and Darby (1979).
} 
alone can explain aggregate U.S. capital formation. We find that lifetime consumption and earnings profiles do not exhibit the kind of shapes needed to generate substantial life-cycle savings. Log linear approximations to these profiles suggest that growth rates of real earnings slightly exceed growth rates of real consumption over the lifetime. Since the life-cycle theory strongly relies on a lifetime growth rate of consumption in excess of the growth rate of earnings, the life-cycle theory of savings with no intergenerational transfers is a very poor description of the process of capital accumulation in the U.S. economy.

Our findings are in agreement with recent studies by White (1978) and Darby (1979) and rationalize other stylized facts about the U.S. economy at odds with the life-cycle theory. Mirer presents evidence from social security data that "the aged do not run down their wealth during their lifetime" (1979, p. 442). Indeed, after he adjusts for intercohort differences in wealth at retirement, Mirer finds "that wealth clearly increases with age" (1979, p. 442). Darby points out that, although the ratio of expected retirement years to expected life span increased by 67 percent from 1890 to 1930, aggregate savings rates showed no increase during this period as would be predicted by the life-cycle theory (1979, pp. 22-28). Atkinson (1971) and Oulton (1976) construct life-cycle models to determine how much of observed British inequality of wealth may be explained by this theory. The answer is, very little. After taking into account inequality in ageearnings profiles and realized rates of return, Oulton concludes, "The results indicate that none of these factors, either singly or in combination, are capable of accounting for a substantial proportion of actual wealth inequality" (1976, p. 99).

Section I presents a theoretical framework for considering the importance of intergenerational transfers to aggregate capital accumulation. Section II discusses the procedure to estimate the stock of life-cycle wealth. The data are described in Section III. Section IV presents and intuitively motivates the findings. The sensitivity of the findings to reasonable possible errors in the data and estimation procedure is also considered. The fifth section attempts to account for the residual between total U.S. wealth and the stock of life-cycle wealth using the limited information available on actual intergenerational transfers. The sixth and final section of the paper presents the conclusions and discusses some of their implications.

\section{Life-Cycle and Transfer Wealth-a Theoretical Framework}

The division of the stock of wealth, $W$, into life-cycle and transfer components, $L$ and $T$, respectively, is easily understood by consider- 
ing a 3-period model of economic growth with identical individuals in each age cohort. At a point in time, aggregate wealth in the economy is the sum of individual wealth holdings. Let $W_{i}$ stand for the wealth holdings of a representative individual of age $i$, and let $P_{i}$ stand for the population of individuals age $i$; then

$$
W=W_{1} P_{1}+W_{2} P_{2}+W_{3} P_{3} .
$$

The $W_{i}$ 's equal, by definition, accumulated flows of net received transfers plus accumulated flows of earnings net of government taxes less government transfers less accumulated flows of consumption, where accumulation takes place at the after-tax interest rate $r$. Let $T_{i j}^{k}$ be the net transfer received at age $i$ from individuals age $j$ for individuals who are currently age $k$. For example, $T_{12}^{3}$ represents the net transfer (which may be positive or negative) that a current 3-periodold individual received at the time he or she was 1 period old from individuals who were then 2 periods old. Let $e_{i}^{k}$ and $c_{i}^{k}$ represent the earnings and consumption of $k$-period-old individuals when they were $i$ periods old. Assuming that earnings, consumption, and transfers occur at the end of each period, $W_{1}$, the wealth of age 1 individuals, equals zero. With this notation, $W_{2}$ and $W_{3}$ may be expressed as:

$$
\begin{aligned}
W_{2}= & \left(T_{12}^{2}+T_{13}^{2}\right)(1+r)+\left(e_{1}^{2}-c_{1}^{2}\right)(1+r) \\
W_{3}= & \left(T_{12}^{3}+T_{13}^{3}\right)(1+r)^{2}+\left(T_{21}^{3}+T_{22}^{3}\right)(1+r) \\
& +\left(e_{1}^{3}-c_{1}^{3}\right)(1+r)^{2}+\left(e_{2}^{3}-c_{2}^{3}\right)(1+r) .
\end{aligned}
$$

Combining (1) and (2) yields:

$$
W=T+L,
$$

where $T=\left(T_{12}^{2}+T_{13}^{2}\right)(1+r) P_{2}+\left[\left(T_{12}^{3}+T_{13}^{3}\right)(1+r)^{2}+\left(T_{21}^{3}+T_{23}^{3}\right)\right.$ $(1+r)] P_{3}$ and $L=\left(e_{1}^{2}-c_{1}^{2}\right)(1+r) P_{2}+\left[\left(e_{1}^{3}-c_{1}^{3}\right)(1+r)^{2}+(1+r)\right.$ $\left.\left(e_{2}^{3}-c_{2}^{3}\right)\right] P_{3}$.

Equation (3) is the fundamental accounting relationship analyzed in this paper. Transfer wealth, $T$, corresponds to accumulated net received transfers, while life-cycle wealth, $L$, corresponds to accumulated earnings less accumulated consumption. Clearly, in a world with no intergenerational transfers, $T$ would equal zero and $W$ would equal $L$. Our first goal is to establish the relative magnitudes of the two components $T$ and $L$ and thereby determine whether U.S. wealth holdings can be predominantly explained by life-cycle savings. Since substantially less information is available about the values of the $T_{i j}^{k}$, most of this paper is devoted to calculating the value of $L$. Section $\mathrm{V}$ does, however, attempt to estimate $T$ directly using fragmentary data and invoking steady-state assumptions.

If the economy is in a steady state, net intergenerational transfers 
received at a given age are constant through time, so that:

$$
\begin{aligned}
& T_{12}=T_{12}^{2}=T_{12}^{3} \\
& T_{13}=T_{13}^{2}=T_{13}^{3} \\
& T_{21}=T_{21}^{3} \\
& T_{23}=T_{23}^{3} .
\end{aligned}
$$

Under the assumption that population grows at a constant rate $n$,

$$
P_{1}=P_{3}(1+n)^{2} \text { and } P_{1}=P_{2}(1+n) .
$$

Since transfers received by age group $i$ from age group $j$ equal the negative of group $j$ 's transfers from age group $i$,

$$
T_{i j} P_{i}=-T_{j i} P_{j},
$$

and

$$
T_{12} P_{1}=-T_{21} P_{2} .
$$

From (4), (5), (6), and (7), $T$ may be expressed in the steady state as: ${ }^{3}$

$$
\begin{aligned}
T= & P_{1}\left\{T_{13}\left[\frac{1+r}{1+n}+\frac{(1+r)^{2}}{(1+n)^{2}}\right]\right. \\
& \left.+T_{12} \frac{(1+r)^{2}}{(1+n)^{2}}+T_{23} \frac{(1+r)}{(1+n)^{2}}\right\} .
\end{aligned}
$$

Under the assumption that $r=n, T$ equals the yearly net flow of transfers from old to young cohorts, $t$, multiplied by the transferweighted age gap, $g$, between donors and recipients:

$T=\left[P_{1}\left(T_{12}+T_{13}\right)+P_{2} T_{23}\right] \cdot\left[\frac{T_{12} P_{1}+2 T_{13} P_{1}+T_{23} P_{2}}{P_{1}\left(T_{12}+T_{13}\right)+P_{2} T_{23}}\right] \equiv t \cdot g .(9)$

If $r$ exceeds (is less than) $n$, accumulated transfer wealth will exceed (be less than) the annual flow of transfers times the weighted average age gap. Equations (8) and (9) show that the contribution of transfers to the total stock of wealth depends critically on both the volume of the annual flow of transfers and the age span of transfers. Equation (8) is invoked in Section $V$ to directly estimate the size of $T$.

The second goal of this paper is to ask the economic question, How would the U.S. capital stock, $W$, change if, because of changes in taxes or tastes, intergenerational transfer wealth, $T$, was reduced? Since consumption, leisure, and transfer decisions are jointly determined it is important to examine the possibility that changes in transfers might

\footnotetext{
${ }^{3}$ By examining (8), one can see that $T$ corresponds simply to the accumulated holdings of transfers received by people who are currently alive from people who are currently dead.
} 
induce or be associated with changes in consumption and earnings paths and thus alter the life-cycle component of wealth. In addition to recognizing interdependencies between transfer wealth and life-cycle wealth, the effect of changes in transfer behavior on capital formation may be examined in both partial and general equilibrium contexts. The partial equilibrium change in $W$ resulting from a reduction in $T$ holds wage rates and interest rates constant and corresponds to a shift in the household supply curve of capital. This paper considers only the steady-state partial equilibrium impact of changes in transfers on the capital stock. A calculation of the general equilibrium effect requires taking account of the responsiveness of the level and shapes of earnings, consumption, and lifetime transfer profiles to changes in capital accumulation. ${ }^{4}$

The Steady-State Partial Equilibrium Reduction in Capital Intensity Arising from a Reduction in Intergenerational Transfers

In order to analyze the partial equilibrium reduction in the stock of wealth, we first note that life-cycle wealth, $L$, equals accumulated earnings minus accumulated consumption. Accumulated earnings, in turn, equals accumulated wages at full-time work minus the accumulated value of leisure. Letting $C$ stand for accumulated consumption, $S$ for accumulated full-time wages, and $M$ for the accumulated value of leisure, equation (3) becomes:

$$
W=T+S-M-C .
$$

The partial equilibrium percentage reduction in $W$ for a percentage change in transfer wealth, $T$, equals:

$$
\frac{\partial W}{\partial T} \frac{T}{W}=\left(1-\frac{\partial M}{\partial T}-\frac{\partial C}{\partial T}\right) \frac{T}{W} .
$$

Equation (10) states that the proportionate reduction in the capital stock equals the share of transfer wealth in aggregate wealth, $T / W$, minus two additional terms indicating how accumulated earnings and accumulated consumption respond to changes in transfers.

Our analysis of the response terms $\partial M / \partial T$ and $\partial C / \partial T$ assumes that the utility of consumption and leisure is separable from the utility derived from intergenerational transfers. This assumption implies that the marginal rates of substitution between consumption and leisure at different points in time are independent of the level of

\footnotetext{
${ }^{4}$ Kotlikoff (1979) demonstrates that general equilibrium changes in capital intensity can be substantially smaller than partial equilibrium changes.

${ }^{5}$ Because wage rates are held constant in this partial equilibrium analysis, $\partial S / \partial T$ equals zero.
} 
intergenerational transfers. Two examples of utility functions exhibiting this property are:

$$
\begin{aligned}
U_{0}= & \log C_{0}+\log C_{1}+\log C_{2}+\log l_{1} \\
& +\log l_{2}+\log l_{3}+\alpha \log T_{12}+\alpha \log T_{13} \\
& +\alpha \log T_{21}+\alpha \log T_{23}+\alpha \log T_{31}+\alpha \log T_{32}
\end{aligned}
$$

and

$$
\begin{aligned}
U_{0}= & \log C_{0}+\log C_{1}+\log C_{2}+\log l_{1} \\
& +\log l_{2}+\log l_{3}+\alpha U_{1} .
\end{aligned}
$$

The term $U_{0}$ stands for the utility of a representative individual of generation zero. The terms $l_{1}, l_{2}$, and $l_{3}$ correspond to leisure in different periods. In (11) the individual derives utility directly from the level of net transfers. In $\left(11^{\prime}\right)$ the individual derives utility from the utility, $U_{1}$, of his descendants. This is an example of an "overlapping utility function." For both types of separable utility functions the marginal rates of substitution between consumption and leisure are independent of the level of $\alpha$, the preference parameter influencing the size of transfers. In addition, the first-order conditions for the optimal choice of consumption and leisure involve the equality between these marginal rates of substitution and the relative prices of consumption and leisure at different ages. Hence, neither changes in transfer preferences nor taxes on intergenerational transfers that affect only the price of transfers but not the price of consumption or leisure will alter the first-order conditions.

Given the levels of transfers, the utility-maximizing levels of consumption and leisure can be separately derived from these first-order conditions and the lifetime budget constraint given below:

$$
\begin{gathered}
C_{1}+\frac{C_{2}}{1+r}+\frac{C_{3}}{(1+r)^{2}}+M_{1}+\frac{M_{2}}{1+r}+\frac{M_{3}}{(1+r)^{2}}=s_{1} \\
+\frac{s_{2}}{1+r}+\frac{s_{3}}{(1+r)^{2}}+T_{12}+T_{13}+\frac{T_{21}}{1+r}+\frac{T_{23}}{1+r} \\
+\frac{T_{31}}{(1+r)^{2}}+\frac{T_{32}}{(1+r)^{2}} .
\end{gathered}
$$

In equation (11), $M_{1}, M_{2}$, and $M_{3}$ are the values of leisure in periods 1,2 , and 3 (by value of leisure we mean the number of units of leisure times the price [wage] per unit). The terms $s_{1}, s_{2}$, and $s_{3}$ are full-time wages in periods 1,2 , and 3. Equation (12) indicates that lifetime consumption and leisure are financed by full-time lifetime earnings plus net lifetime received transfers. The separability assumption im- 
plies that changes in preferences or taxes that alter the values of the $T_{i j}$ have only an income effect on the choices of consumption and leisure over the lifetime.

We now demonstrate that this income effect of a change in transfers is identically zero for the case that $r$ equals $n .{ }^{6}$ Using (5) and (6) to rewrite (12), we obtain:

$$
\begin{aligned}
C_{1}+\frac{C_{2}}{1+r}+ & \frac{C_{3}}{(1+r)^{2}}+M_{1}+\frac{M_{2}}{1+r}+\frac{M_{3}}{(1+r)^{2}}=s_{1} \\
+\frac{s_{2}}{1+r}+ & \frac{s_{3}}{(1+r)^{2}}+\frac{T_{12}(r-n)}{(1+r)}+\frac{T_{23}(r-n)}{(1+r)^{2}} \\
& +\frac{T_{13}\left[(1+r)^{2}-(1+n)^{2}\right]}{(1+r)^{2}} .
\end{aligned}
$$

We can also write the budget constraint $\left(12^{\prime}\right)$ in terms of aggregate transfer wealth per young person $T^{\prime}$ where $T^{\prime}=T / P_{1}$ :

$$
\begin{gathered}
C_{1}+\frac{C_{2}}{1+r}+\frac{C_{3}}{(1+r)^{2}}+M_{1}+\frac{M_{2}}{1+r}+\frac{M_{3}}{(1+r)^{2}} \\
=s_{1}+\frac{s_{2}}{1+r}+\frac{s_{3}}{(1+r)^{2}}+\frac{(r-n)(1+n)^{2} T^{\prime}}{(1+r)^{3}} .
\end{gathered}
$$

As is clear from $\left(12^{\prime}\right)$ and $\left(12^{\prime \prime}\right)$, when $r=n$, lifetime consumption and leisure are financed solely out of lifetime full earnings; all of the accrued interest on received transfers, as well as the principle itself, is used to maintain steady-state transfers per head at a constant level. When $r=n$, reducing transfers has no impact on the steady-state budget constraint, and the terms $\partial M / \partial T$ and $\partial C / \partial T$ in (10) are zero (i.e., since lifetime consumption and earnings paths stay the same when $r=n$, steady-state life-cycle wealth, $L$, will be unaltered by changes in steady-state transfer wealth, $T$ ). Thus, any decline in transfer wealth, $T$, will reduce total wealth, $W$, dollar for dollar in partial equilibrium when $r=n$.

In the case that $r$ differs from $n$, steady-state changes in the level and pattern of transfers (the $T_{i j}$ terms) affect the steady-state budget constraint only insofar as they alter the stock of transfer wealth $T$. This is a general proposition that can easily be shown to hold independent of the number of periods in the model. When $r$ exceeds $n$, part of lifetime consumption and leisure is financed by lifetime transfers. Again, under the separability assumption, the reduction in trans-

\footnotetext{
${ }^{6}$ In the case of a tax on transfers, the income effect of a change in transfers when $r=$ $n$ will be zero only for the case of a compensated tax on transfers. Compensated rather than uncompensated tax changes are the appropriate focus of studies of government tax policies toward savings. See Diamond 1970 and Kotlikoff and Summers 1979.
} 
fers has simply an income effect on consumption and leisure and, assuming both are normal goods, will reduce lifetime consumption and raise lifetime earnings. In (10) both $\partial M / \partial T$ and $\partial C / \partial T$ will be positive when $r$ exceeds $n$. The reverse will be true when $n$ exceeds $r$. It is easy to demonstrate that introducing labor-augmenting productivity growth simply requires relabeling $n$ everywhere as the population growth rate plus the productivity growth rate. In the case of productivity growth, the steady state is characterized by a constant level of transfers per effective worker.

The value of these terms depends on the particular preferences determining the levels and shapes of consumption and leisure paths. As one example, table 1 gives the value of the transfer wealthadjustment factor $[1-(\partial M / \partial T)-(\partial C / \partial T)]$ for a particular specification of preferences for consumption and leisure and for different values of $r$ and $n$. The example assumes a 55-year life span and uses the logarithmic utility function with time-preference parameter $\rho$ and leisure-preference parameter $\alpha:^{7}$

$$
U=\int_{0}^{D} \log C_{t} e^{-\rho t} d t+\alpha \int_{0}^{D} \log l_{t} e^{-\rho t} d t
$$

The $l_{t}$ terms in (13) are units of leisure at different points in time. The calculations underlying table 1 are presented in Kotlikoff and Summers (1980, appendix A).

The figures in table 1 indicate that the response of consumption and labor supply can be quite important in determining the final partial equilibrium effect of a reduction in transfers when the interest rate differs from the economy's growth rate. For the specific logarithmic function chosen here, a real interest rate that is 1 percent higher than the rate of population plus productivity growth generates total wealth response numbers approximately equal to 0.7 . If, on the other hand, the rate of population plus productivity growth exceeds the real interest rate by 1 percent, reducing transfer wealth by $\$ 1.00$ reduces aggregate wealth by $\$ 1.40$.

For the United States the annual rate of population growth has averaged 1.40 percent from 1900 through 1974 , the period of this study (see U.S. Department of Commerce 1975, pt. 1, p. 8). Productivity growth as measured by the annual percentage change in real GNP per man-hour has averaged 2.20 percent over this period. ${ }^{8}$

\footnotetext{
${ }^{7}$ The utility function in (13) corresponds only to that part of total utility pertaining to consumption and leisure. Any set of preferences for transfers may be added to (13) as long as utility of consumption and leisure is separable from the utility of transfers. The assumption of a steady state with productivity growth also requires that the entire utility function be homothetic.

${ }^{8}$ U.S. Department of Commerce 1973, series A167 and A168, p. 210, and U.S. Department of Labor 1978, p. 336. Kendrick's series of output per man-hour is used for the years 1900-1910, and the BLS series thereafter.
} 
TABLE 1

Transfer Wealth Adjustment Factor

\begin{tabular}{llcc}
\hline \hline & & & $1-\frac{\partial M}{\partial T}-\frac{\partial C}{\partial T}$ \\
\hline$r$ & $n$ & $\rho$ & .73 \\
.02 & .01 & .02 & .71 \\
.02 & .01 & .03 & 1.00 \\
.02 & .02 & .02 & 1.40 \\
.02 & .03 & .02 & 2.00 \\
.03 & .04 & .02 & .58 \\
.03 & .01 & .01 & .48 \\
.03 & .01 & .05 & .71 \\
.03 & .02 & .03 & 1.00 \\
.03 & .03 & .03 & 1.43 \\
.04 & .04 & .03 & .45 \\
.04 & .01 & .01 & .30 \\
.04 & .01 & .07 & .49 \\
.04 & .02 & .04 & .70 \\
.04 & .03 & .04 & 1.00 \\
\hline
\end{tabular}

Adding 1.4 to 2.2 yields 3.6 percent as the rate of population plus productivity growth. This paper calculates a portfolio-weighted net nominal rate of return for the U.S. economy from 1900 through 1974. After subtracting inflation, the real annual net after-tax rate of return in the U.S. economy averaged 4.5 percent between 1900 and $1974 .^{9}$

The fact that real interest rates have on average exceeded growth rates suggests that part of U.S. consumption and leisure may well have been financed by interest earned on intergenerational transfers. Hence, a dollar reduction in transfer wealth can be expected to reduce aggregate wealth by less than $\$ 1.00$. The calculated 1 percent gap between $r$ and $n$ suggests that eliminating transfer wealth in the U.S. economy would reduce total wealth by about 70 percent of the amount of transfer wealth. While the 70 percent figure is meant to be suggestive rather than precise, it appears that almost any choice of preferences would yield offset factors not far from 70 percent. ${ }^{10}$ That

\footnotetext{
${ }^{9}$ To obtain a real net rate of return series, we subtract the annual percentage change in the CPI from our net nominal return series indicated in U.S. Department of Commerce (1975, pt. 1, pp. 210-11, table B2) and U.S. Department of Commerce (1978, p. 490).

${ }^{10}$ These calculations were performed for the more general isoelastic utility function. A wide range of parameter values for rates of risk aversion and time preference produced values of $[1-(\partial M / \partial T)-(\partial C / \partial T)]$ ranging from 0.6 to 0.75 when $r$ exceeds $n$ by 1 percent. While it is unclear what utility function is most appropriate, these parameter values cover a wide range of different shapes of consumption and leisure profiles and, we presume, bound the likely response. The assumption implicit in these utility functions that consumption and leisure respond homothetically to changes in
} 
is, the life-cycle offset to a change in transfer wealth is likely to be small.

\section{The Estimation of Life-Cycle Wealth-Methodological Approach}

Total life-cycle wealth in the U.S. economy equals the sum over all living persons in the economy of life-cycle assets. Each person's lifecycle assets correspond to his or her accumulated earnings less accumulated consumption where accumulation occurs at the actually realized rates of return. If data existed detailing each person's earnings, consumption, and realized rate of return on assets at each point in time in the past, it would be easy to check whether U.S. wealth holdings could be explained predominantly by life-cycle accumulation.

Obviously, such detailed individual specific data are not available. However, historical data for the United States on aggregate earnings, aggregate consumption, rates of return, and age-earnings and ageconsumption profiles may be used to carry out this life-cycle asset computation on a cohort-by-cohort basis. This paper treats individuals of each sex within an age cohort as identical and estimates the average excess of after-tax earnings plus government transfers over consumption experienced by members of that age-sex cohort during each of their adult years in the past. These differences are then accumulated up to 1974 using historical net nominal interest rates. The total over all age-sex cohorts of these accumulated life-cycle assets is then compared with the 1974 value of total U.S. private net worth.

Life-cycle wealth of the age-sex cohort that is age $a$ and $\operatorname{sex} j$ in $1974, L_{j}(a)$, is given by

$$
\begin{aligned}
L_{j}(a) \equiv & \sum_{i=18}^{a}\left\{\left[\bar{E}_{j}(a, i)+\bar{G}_{j}(a, i)-\bar{C}_{j}(a, i)\right]\right. \\
& \left.\prod_{k=i}^{a}[1+r(a, k)]\right\} P_{j}(a) .
\end{aligned}
$$

\footnotetext{
transfers may be inappropriate. Even if the utility function is homothetic, capital market constraints precluding borrowing when young against future earnings may make the consumption and leisure response to a reduction in transfers nonhomothetic. These capital market constraints may not be binding in the presence of transfers because the excess of consumption over earnings when young is financed by the received transfers. Eliminating or reducing transfers could make these capital market constraints binding and require proportionately less consumption and leisure when young than when old.
} 
In equation (13), $P_{j}(a)$ stands for the number of people alive in 1974 who are age $a$ and $\operatorname{sex} j$. The terms $\bar{E}_{j}(a, i), \bar{G}_{j}(a, i)$, and $\bar{C}_{j}(a, i)$ are, respectively, the average after-tax earnings, government transfers, and consumption of the age $a$-sex $j$ cohort at the time its members were age $i$. Age 18 is taken as the age of adulthood. Consumption expenditures by adults on children under the age of 18 are considered to be a part of adult consumption rather than intergenerational transfers. ${ }^{11}$ The term $r(a, k)$ is the economy-wide annual net nominal interest rate received by the age $a$ cohort during the year the cohort's members were $k$ years old.

Our estimate of total life-cycle assets in the economy in 1974 equals the sum over all age-sex cohorts of the estimated values of $L_{j}(a){ }^{12}$ The difference between life-cycle wealth and total U.S. wealth in 1974 is our estimate of transfer wealth.

Calculation of Longitudinal Profiles of Net Earnings, Government Transfers, and Consumption

The essential idea involved in these calculations is to use crosssectional distribution profiles to allocate aggregate flows of net earnings, government transfers, and consumption to different age-sex cohorts in a given year. By performing this computation for each year from 1900 to 1974 , we obtain the longitudinal profiles $\bar{E}_{j}(a, i), \bar{G}_{j}(a, i)$, and $\bar{C}_{j}(a, i)$ as $i$ varies.

To illustrate the computation for $\bar{E}_{j}(a, i)$, we define the following terms: $\bar{e}_{t}$ is the average earnings of 40 -year-old male workers in year $t$; $g_{m}(a, t)$ is the ratio of average earnings of male workers at age $a$ in year $t$ to average earnings of 40 -year-old male workers in year $t ; g_{f}(a, t)$ is the ratio of average earnings of female workers at age $a$ in year $t$ to average earnings of 40 -year-old female workers in year $t ; \lambda_{t}$ is the ratio of average earnings of 40 -year-old female workers to average earnings of 40-year-old male workers in year $t ; \alpha_{m}(a, t)$ is the percentage of males age $a$ with work experience in year $t ; \alpha_{f}(a, t)$ is the percentage of females age $a$ with work experience in year $t ; H_{t}$ is total after-tax labor income in year $t ; P_{m}(a, t)$ is the population of males age $a$ in year $t$; and $P_{f}(a, t)$ is the population of females age $a$ in year $t$. Given information on all of the above variables except $\bar{e}_{t}$, equation (14) is used to solve for $\bar{e}_{t}$ :

\footnotetext{
${ }^{11}$ Treating consumption of children under age 18 as their own life-cycle consumption would greatly reduce our estimate of life-cycle wealth and greatly increase our estimate of transfer wealth. The age of adulthood is somewhat arbitrary, but 18 appears to be a reasonable number and of general interest.

${ }^{12}$ Assets of children under age 18 are assumed to be completely inherited and are not included in life-cycle wealth.
} 


$$
\begin{aligned}
H_{t}= & \bar{e}_{t} \sum_{a=18}^{100}\left[g_{m}(a, t) \alpha_{m}(a, t) P_{m}(a, t)\right. \\
& \left.+\lambda_{t} g_{f}(a, t) \alpha_{f}(a, t) P_{f}(a, t)\right] .
\end{aligned}
$$

Given $\bar{e}_{t}, \bar{E}_{m}(a, i)$ for males and $\bar{E}_{f}(a, i)$ for females satisfy:

$$
\begin{aligned}
& \bar{E}_{m}(a, i)=\bar{E}_{m}[a, a-(1974-t)]=\bar{e}_{t} g_{m}(a, t) \alpha_{m}(a, t), \\
& \bar{E}_{f}(a, i)=\bar{E}_{f}[a, a-(1974-t)]=\bar{e}_{t} \lambda_{t} g_{f}(a, t) \alpha_{f}(a, t) .
\end{aligned}
$$

The procedure for computing the longitudinal profiles of consumption, $\bar{C}_{j}(a, i)$, is identical to that just described for earnings; a cross-sectional profile of relative consumption by age and sex is used to distribute aggregate U.S. consumption in each year to different age-sex cohorts.

\section{Calculation of Net Nominal Interest Rates Series}

The interest rate term $r(a, i)$ on (13) depends only on the year $t$ since $r(a, i)=r[1974-(a-i)]=r(t)$. The computation is performed using two different interest rate time series. Series 1 was calculated by dividing U.S. wealth holdings into six separate assets, estimating a rate of return series for each asset, and then weighting each asset's rate of return by its share in the U.S. portfolio for the particular year in question.

Series 2 is based on the wealth augmentation relation:

$$
W_{t+1}=W_{t}\left(1+r_{t}\right)+E_{t}+G_{t}-C_{t} .
$$

Equation (18) indicates that private U.S. net worth in year $t+1$ equals U.S. net worth in year $t$ plus savings in year $t$. Savings in year $t$ is, in turn, equal to net income on assets, $r_{t} W_{t}$, plus after-tax labor income and government transfers, $E_{t}$ and $G_{t}$, less aggregate consumption in year $t, C_{t}$. Equation (18) is solved for $r_{t}$ using time-series data on $W_{t}, E_{t}, G_{t}$, and $C_{t}$.

\section{Description of Data Used to Calculate Life-Cycle Wealth}

This section describes sources and procedures for several of our data series. Kotlikoff and Summers (1980) provide a detailed description of all the data and adjustments to the data used in calculations.

Information on compensation of employees after 1929 is obtained from the National Income Accounts and, for the years 1909-29, from Leven, Moulton, and Warburton (1934) and Kuznets (1941, 1946). Prior to 1909, employee compensation is imputed from Kendrick's estimates of net national product using the ratios of employee com- 
pensation to national product from 1909 to $1918 .{ }^{13}$ The imputation of labor income to the self-employed follows Christensen (1971). The number of proprietors is multiplied by the average earnings of fulltime equivalent employees. The chief bias here is simply that the self-employed may earn more or less on average than employees. To insure that the results do not reflect a substantial underestimate of entrepreneurial earnings, the estimate of entrepreneurial earnings for each year is increased by 20 percent.

Estimates of state and federal income taxes paid on labor income were obtained from IRS Statistics of Income and the National Income and Product Accounts. Combined employer and employee social security and health insurance taxes were obtained from the Social Security Annual Statistical Supplement for various years.

Estimates of the age-earnings profiles for men and women were obtained by fitting separate regressions to social security estimates of median annual earnings of workers at different ages for the years 1950 through $1975 .{ }^{14}$ The general shapes of the profiles predicted by the regressions are quite similar throughout the 1950-75 period. For the years prior to 1950 , the predicted male and female age-earnings profiles for the year 1955 were used..$^{15}$

The value of $\lambda_{t}$, the ratio of average earnings of 40 -year-old female workers to average earnings of 40 -year-old male workers in year $t$, was taken to be .55 throughout the period. This appears to be an upperbound value for $\lambda_{t}$ (see Kotlikoff and Summers 1980, p. 46, n. 35).

Values for work experience rates by age and sex, $\alpha_{m}(a, t)$ and $\alpha_{f}(a$, $t$ ), are available only after 1959 . Substantially more information, especially for the early 1900 s, is available on labor force participation rates by age and sex. Regression analysis for the post-1959 period indicates that work experience rates can be predicted quite well by functions of age and labor force participation rates. This post-1959 regression was used to estimate the $\alpha$ function for each year from 1900 to 1974 based on labor force participation rates for the appropriate year. The labor force participation rates equal the values predicted from regressions of labor force participation rates on fifth-order age polynomials for each sex and for different census years.

While cross-sectional distribution functions by sex and age were computed for social security and medicare transfers, we assumed that

${ }^{13}$ See Leven et al. 1934, p. 155; Kuznets 1941, pp. 322-23; and Kendrick's series A6 and B61 in U.S. Department of Commerce (1973), pp. 182, 222. Because of limitations on population estimates on individuals above age 85 , we treat all individuals who were above age 85 in 1974 as if they were age 85 . Since 85-year-olds in 1974 did not reach the age 18 until 1907, we really do not use any data for the years prior to 1907 in this paper.

${ }^{14}$ These and other regression results are reported in Kotlikoff and Summers (1980).

${ }^{15}$ The year 1955 was chosen because by 1955 the social security data cover most of the private economy's work force. 
other transfers, including veterans' benefits and welfare payments, were distributed in the cross-section over the years 1900-1974 according to that year's age-earnings distributions.

Total consumption expenditure, $Z_{t}$, is taken from National Income Accounts after 1929 and from Kendrick prior to 1929. Ideally one should subtract expenditures on consumer durables and add imputed rent on consumer durables to obtain true economic consumption. The difficulties of implementing this for the pre-1929 years led us to simply use the consumer expenditure series. In any case, there appears to be very little difference between the consumer expenditure series and the true economic consumption series. ${ }^{16}$

The cross-sectional consumption distribution functions were obtained from the 1960 and 1972-73 Consumer Expenditure Survey (CES) tapes. Unfortunately, similar data are not available to generate these profiles for earlier years. Life-cycle wealth is computed using the 1972-73 cross-sectional profiles throughout the period 1900-1974. The 1960 profiles generated essentially the same level of life-cycle wealth.

In distributing total household consumption to household members, household heads and their spouses are assumed to consume equally; all other household members, including children, were allocated 50 percent of the household head's consumption. The total consumption of children under the age of 18 was then reallocated to the household head and spouse, assigning each one half of children's consumption in the case of two spouses, or giving all the children's consumption to the household head if he or she was single. The general shape of the profiles was quite insensitive to the assumption that other household members and children consume only 50 percent of the consumption level of the household head. The 50 percent assumption generated slightly more life-cycle wealth and is the one used.

Net nominal interest rate series 1 is generated from data on historical rates of return and Goldsmith and Lipsey's (1963) data on portfolio shares. From Goldsmith and Lipsey's balance sheets we constructed seven asset categories plus liabilities. These are tangible, noncorporate business assets including land and structures, residential land and structures, money, short-term claims (savings accounts and U.S. Treasury bills), corporate stock, long-term corporate bonds, and U.S. savings bonds. A rate of return series was calculated for each asset as well as the liabilities. A weighted rate of return was computed

${ }^{16}$ Christensen and Jorgenson's (1973) "true" consumption series (p. 17) is very close to the NIA series for the years 1929-69. The Christensen and Jorgenson series is slightly higher for most years; using the Christensen and Jorgenson series for the post-1929 years would, therefore, lead us to calculate less life-cycle wealth. 
taking the share of each item in net worth during the period considered as the weight. The nominal rates of return were converted to after-tax nominal rates of return using average income tax rates for each year. The series 2 net nominal interest rates were computed for the post-1929 period using equation (22). Reliable net worth data are not available until 1929. In the computation the series 2 rates from the pre-1929 years are filled in with the series 1 values.

\section{The Size of Life-Cycle Wealth}

At the end of 1974 total net worth in the U.S. economy equaled $\$ 4.154$ trillion. Of the $\$ 4.154$ trillion, $\$ 134$ billion represent the tangible assets of nonprofit institutions (see FRB-MIT balance sheets); in 1974 nonprofit institutions owned 4.4 percent of corporate equities (SEC 1977, p. 11). Under the assumption that this percentage applies to all other financial assets, total net worth of nonprofit institutions in 1974 would equal $\$ 270$ billion. ${ }^{17}$ After subtracting $\$ 270$ billion from $\$ 4.154$ trillion, the 1974 net worth figure for the noninstitutional household sector is $\$ 3.884$ trillion. This is the number to compare with the life-cycle wealth calculations.

In addition to presenting total life-cycle wealth of individuals, a second life-cycle wealth concept, LCW2, is calculated that adds to LCW1 an upper-bound estimate of accumulated interspousal transfers. Many economists would include within their definition of lifecycle wealth the amount of accumulation that arises from interspousal transfers. Interspousal transfers give rise to wealth accumulation, first, because wives are on average younger than husbands and, second, because females live longer than males. Since it is conceptually difficult, if not impossible, to exactly trace individual patterns of household formation that involve marriage, divorce, and death, an upper-bound estimate of the stock of interspousal accumulated transfers is added to LCW1. To be specific, at age 21 all males are assumed to marry 18-year-old females. ${ }^{18}$ If either spouse dies prior to reaching

${ }^{17}$ See SEC 1977, p. 11. This assumes that nonprofit institutions have no liabilities.

${ }^{18}$ The 1972-73 CES data indicate that the average age gap between husband and wife is 3 years. The number of deaths in an age-sex cohort in a particular year was obtained by multiplying age-, sex-, and year-specific death rates from the U.S. census bureau's population estimates. Historical Statistics (U.S. Department of Commerce 1975, vol. 1, death rates, series B 181-92, pp. 61-62) are smoothed. Even in the absence of marriage, our LCW2 concept would be of interest because it essentially treats individuals as if their wealth at each moment were fully annuitized; i.e., given the uncertainty of the date of death, individuals in a life-cycle model with no bequest motive would always purchase annuities. Hence, our procedure of essentially passing a cohort's bequest over to surviving members mimics the operation of an annuities market. Thus LCW2 can be thought of as essentially the life-cycle wealth of the U.S. economy if individuals always purchased annuities. 
age 75 , all of his or her individual life-cycle net worth is assumed to be transferred to the surviving spouse; it was furthermore assumed that the surviving spouse does not die prior to age 75. Thus, for example, if a 40 -year-old male dies in 1960 with $\$ 20,000$ of life-cycle wealth, this $\$ 20,000$ is transferred to a 37 -year-old female who is assumed still to be alive 14 years later in 1974 . The $\$ 20,000$ of received transfers is accumulated up to 1974 at the prevailing interest rates and included in life-cycle wealth.

This procedure overestimates accumulated interspousal transfers for three reasons. First, not all transfers of decedents go to surviving spouses or even to surviving relatives in the same age cohort. Second, not all surviving spouses will, themselves, live until age 75 . Rather, many will die much earlier, leaving the bulk of their residual wealth to children or grandchildren. Third, some decedents die without ever having married, leaving their estates to younger cohorts.

Table 2 reports the life-cycle wealth numbers, LCW1 and LCW2, based on interest rate series 1 and series 2 , as well as constant interest rates of 2, 4, 6, 8, and 9 percent. The series 1 values for LCW1 and LCW2 are, respectively, $-\$ 1,036$ and $\$ 502$ billion. The series 2 figures are $-\$ 1,229$ and $\$ 733$ billion. These figures are strikingly small; they are even more surprising in light of assumptions made that bias the calculation toward more life-cycle wealth. ${ }^{19}$ Under the stricter definition of life-cycle wealth, LCW1, life-cycle accumulated hump savings is a large, negative number. The allowance for interspousal transfers yields positive, but very small, estimates of hump savings. The $\$ 733$ billion series 2 LCW2 figure for life-cycle wealth represents only 19 percent of the total 1974 U.S. wealth. These small values for life-cycle wealth do not reflect the choice of interest rates; no historically reasonable constant nominal interest rate will yield significant positive life-cycle wealth. Accumulated intergenerational transfers appear to represent the bulk of the $\$ 3,884$ billion of U.S. wealth holdings in 1974 . Subtraction of 733 from 3,884 gives $\$ 3,151$ billion as the estimate of the 1974 stock of transfer wealth. Taking the .7 ( $r$ exceeds $n$ by about 1 percent) adjustment factor as illustrative, entirely eliminating intergenerational transfers would reduce U.S. wealth by about $\$ 2.2$ trillion in the context of a partial equilibrium, long-run steady-state model.

To explain the large stock of U.S. wealth, the life-cycle theory of savings must rely on a substantial excess of earnings over consumption when young followed by an excess of consumption over earnings

\footnotetext{
${ }^{19}$ These include increasing the labor income of the self-employed by 20 percent, using a high value of .55 for the ratio of female to male earnings at age 40 , assuming that the age-consumption profile is flat after age 75 , and assuming that all earnings after age 75 are zero.
} 


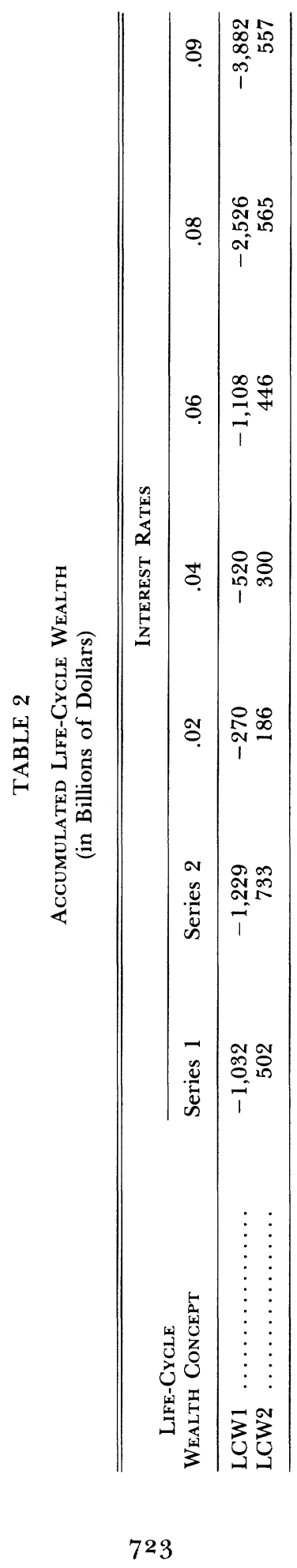




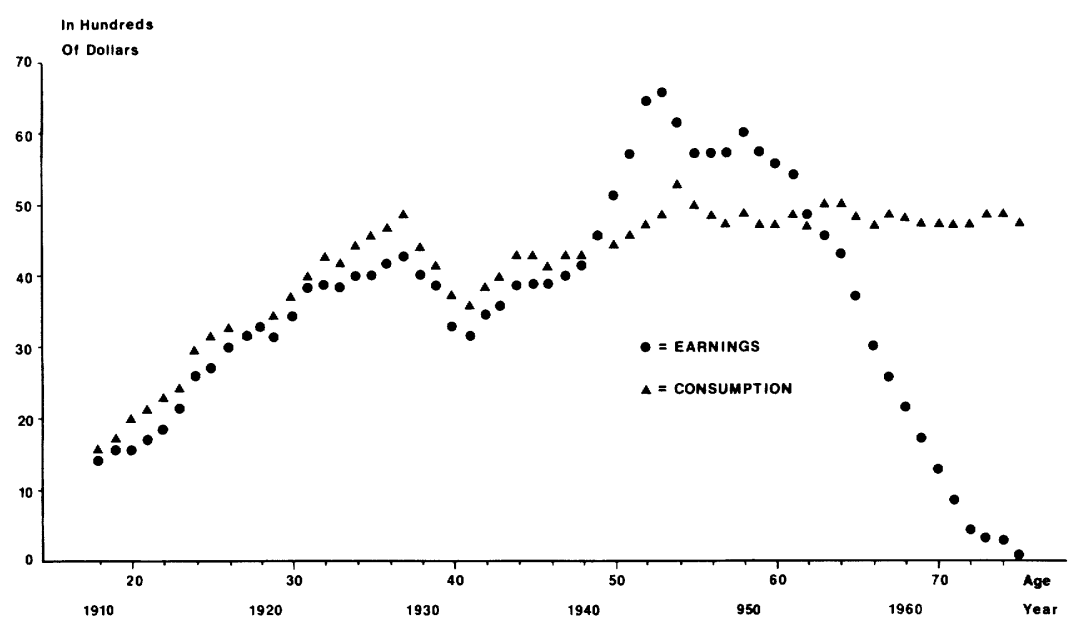

Fig. 1.-Sum of male and female longitudinal average earnings and average consumption profiles, age 18 in 1910 -age 82 in 1974.

when old. The historical reality for the United States is simply that longitudinal earnings and consumption profiles have not exhibited the kinds of shapes required for substantial life-cycle accumulation. For males, earnings profiles greatly exceed consumption profiles over most of the life cycle. For females, however, the opposite is true. Life-cycle wealth starts out negative and remains negative over all ages. Figures 1 and 2 graph longitudinal profiles of the sum of male and female average earnings plus government transfers and average consumption for two different age cohorts. The profiles are presented in real 1967 dollars. The diagrams clearly show that the male excess of earnings over consumption is essentially offset by the female excess of consumption over earnings.

Contrary to the life-cycle simulation studies that have generated substantial life-cycle wealth, the actual growth rate of lifetime consumption does not substantially exceed the actual growth rate in lifetime earnings. ${ }^{20}$ For example, the male age cohort that reached

${ }^{20}$ Roger Gordon has suggested to us that observed age-earnings profiles may differ from true age-earnings profiles to the extent that firms and workers are engaged in implicit contractual arrangements. Firms could pay out to workers less (more) than they truly earn when young and more (less) than they truly earn when old. Some part of a worker's life-cycle saving or dissaving would then be accomplished within the firm and would correspond to a claim (or liability) attached to the firm's assets. While we would strongly contest the empirical validity of this proposition, certainly a very upper-bound estimate of life-cycle savings with firms would be the difference between the market and replacement costs of capital in the corporate sector. Using 0.819 , the average value of $q$ over the period 1952-74 (von Furstenberg 1977) and the 1974 replacement value of corporate capital of $\$ 1.679$ trillion gives an upper-bound estimate of $\$ 304$ billion for this effect. 


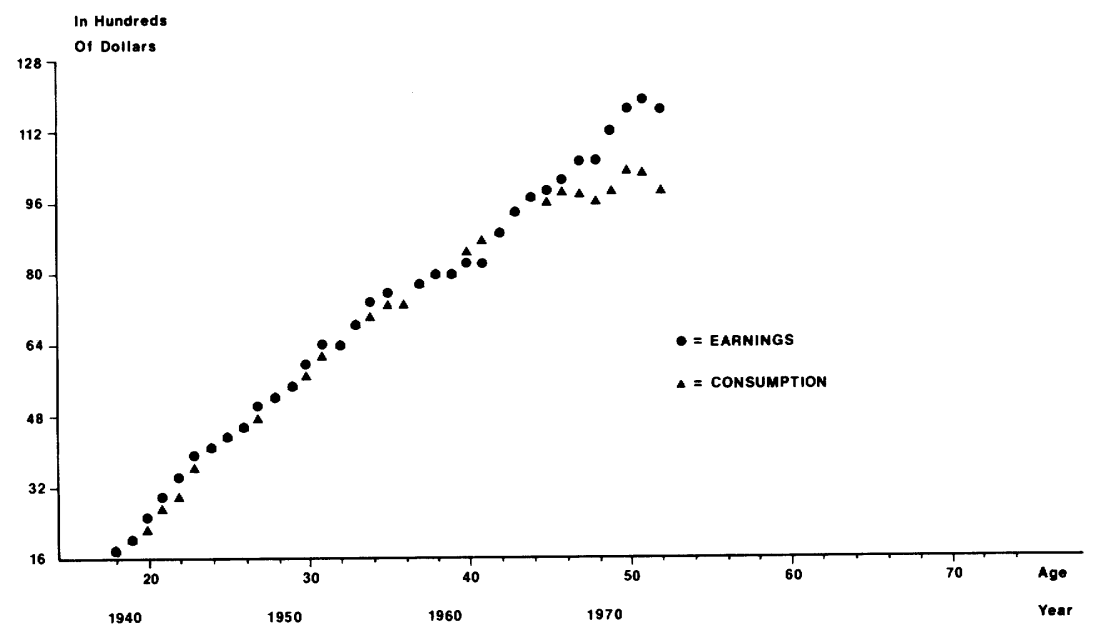

Fig. 2.-Sum of male and female longitudinal average earnings and average consumption profiles, age 18 in 1940-age 52 in 1974.

age 18 in 1920 experienced a growth rate of 2.93 percent in real earnings between ages 18 and 65 . In comparison, the male growth in real consumption between ages 18 and 72 was only 2.32 percent. For the corresponding female cohort, earnings growth was 2.23 percent and consumption growth only 1.72 percent. Real consumption profiles are fairly flat, and real earnings profiles peak in late middle age, not at early ages. Both of these factors militate against the life-cycle theory of savings as an explanation of U.S. wealth holdings.

The large transfer wealth value of $\$ 3.151$ trillion cannot simply be explained as private transfers from old to young offsetting forced government social security and medicare transfers from young to old. Under the Barro (1974) view, introducing unfunded social security into an economy will not lead to a change in consumption but will increase private net transfers from old to young. If Barro's view is correct, it is easy to determine how large private transfers would have been with no social security and medicare system by simply setting all historic social security and medicare benefits and taxes to zero in the calculation. This procedure led to a series 1 value of $\$ 775$ billion and a series 2 value of $\$ 1,094$ billion for LCW2. Hence, even if Barro is correct in his view about unfunded social security, transfer wealth would still have exceeded $\$ 2.79$ trillion in 1974 if there had never been a social security program.

One possible problem with the estimates is that the ageconsumption profiles prior to 1960 may have looked substantially different from those after 1960 . To explore this issue, relative consumption prior to age 40 was reduced by 10 percent and relative 
consumption after age 40 was increased by 10 percent. Thus, $60-$ year-olds were effectively assigned an extra 20 percent consumption relative to 30 -year-olds in every year from 1900 to 1974 . Altering consumption profiles in this manner produced values of -193 for LCW 1 and 1,702 for LCW2 using series 1 and -169 for LCW 1 and 2,178 for LCW2 using series 2 . These numbers are still substantially smaller than the $\$ 3,884$ billion of 1974 U.S. net worth.

Another issue of concern is whether our data series on aggregate flows accurately describe U.S. experience in the 1900s. As mentioned, to insure against underestimation of the labor income of the selfemployed, we have already increased our estimates by 20 percent. Raising this add-on factor to 30 percent increases the series 1 values of LCW1 to -679 and LCW2 to 872 . It is worth noting that eliminating any self-employment add-on factor lowers LCW1 to $-1,739$ and LCW2 to -714 .

A final data issue concerns consumption expenditures of nonprofit institutions as well as contributions of individuals to such institutions. Ideally we should subtract institutional consumption from aggregate consumption and add contributions to these institutions to arrive at total household consumption. While not all the data needed for this adjustment are available, what data are available suggest that the adjustment would be very small and would slightly lower our estimate of life-cycle wealth. ${ }^{21}$

The LCW2 wealth concept effectively deals with possible bias arising from differential survival probabilities between the rich and the poor. This calculation assumes that at least one member of each household survives to age 75 and attributes all household life-cycle accumulation to the surviving spouse(s). Hence, this procedure assumes that rich and poor households have identical survival probabilities, which eliminates this issue of bias.

Another type of aggregation error could arise if some households continually received higher rates of return on their assets than other households. In order to investigate this issue one would need detailed knowledge of the joint distribution of rates of return and household consumption and earnings patterns. Unfortunately, this information cannot be obtained from existing micro data, and this fact precludes a reasonable assessment of the magnitude of this source of error.

\footnotetext{
${ }^{21}$ In 1970 , for example, the level of philanthropic payments of individuals totaled $\$ 16.09$ billion (U.S. Department of Commerce 1975, vol. 1, series H 399-400, p. 359). In comparison, the NIA (U.S. Department of Commerce 1976, p. 90, lines 101 and 102) reported 1970 expenditures of institutions for religious, educational, and welfare activities totaled only $\$ 11.32$ billion.
} 


\section{Explaining the Residual-the Stock of Transfer Wealth}

This section investigates the extent to which U.S. data on intergenerational transfers can explain the large residual between total net worth and the estimates of life-cycle wealth. Unfortunately, there are very few data detailing nontaxed intergenerational transfers. These nonenumerated transfers take many forms. Parents who lend money at below market rates to their children for a down payment on a house or a business are engaged in an intergenerational transfer. A father who makes his son a full partner in a lucrative business can effectively transfer large sums of money with no tax liability to the IRS. Parents who fully or partially support their children through college or after college are making transfers. A grandmother's gift of her expensive wedding china and rings to her granddaughter is an intergenerational transfer. Transfers in these forms, as well as outright monetary gifts, are very rarely reported.

To obtain some idea about how large aggregate intergenerational transfer flows need to be in order to explain a $\$ 3.151$ trillion stock of transfer wealth, consider the multiperiod analogue to equation (8):

$$
T=t \frac{e^{(r-n) D}}{(r-n)}\left[1-e^{(n-r)(G-I)}\right] .
$$

Equation (19) is a simplified expression for the steady-state stock of transfers; the formula assumes that all transfers are given at age $G$ and received at age $I$. The yearly flow of intergenerational transfers is $t$, the age of death $D$, and $r$ and $n$ are rates of interest and population plus productivity growth, respectively. In the case $r=n$, this expression reduces to $T=t(G-I)$, the analogue to equation (9). Table 3 evaluates the age gap factor, that is, the terms multiplying $t$ for various parameter values and taking $D$ to be $55 .{ }^{22}$

Exactly which age gap is appropriate is unclear. ${ }^{23}$ An age gap of 30 allows some significant transfers to grandchildren as well as children. The age gap factor in this case for a .01 excess of $r$ over $n$ is 45 . Hence, to explain $\$ 3,151$ billion in transfer wealth, the yearly flow of transfers would have to equal 3,151 divided by 45 , or $\$ 70$ billion. A 2 percent differential between $(r-n)$, again assuming a 30-year gap, would require only a $\$ 46$ billion annual transfer flow.

The 1962 Federal Reserve Survey of Consumer Finances was used

${ }^{22}$ If we take age 18 as the age of adulthood, the value of 55 for $D$ corresponds to a real-world age of death of 73 .

${ }^{23}$ To precisely calculate a weighted age gap we would need data detailing age of donors and recipients as well as the size of the transfers. Such data are currently unavailable. 
TABLE 3

Age GaP Factor

\begin{tabular}{|c|c|c|c|c|c|c|}
\hline \multirow[b]{2}{*}{$\operatorname{AgE} \operatorname{GAP}(G-I)$} & \multicolumn{6}{|c|}{$r-n$} \\
\hline & -.02 & -.01 & 0 & .01 & .02 & .03 \\
\hline 20 & 8 & 13 & 20 & 31 & 49 & 78 \\
\hline$\ldots \ldots \ldots \ldots$ & 11 & 16 & 25 & 38 & 59 & 92 \\
\hline $30 \ldots \ldots \ldots \ldots \ldots$ & 14 & 20 & 30 & 45 & 68 & 103 \\
\hline $35 \ldots \ldots \ldots \ldots \ldots$ & 17 & 24 & 35 & 51 & 76 & 113 \\
\hline
\end{tabular}

to estimate the bequest portion of the yearly transfer flow. Specifically, the distribution of net worth holdings by age, sex, and marital status was calculated. Next, 1962 mortality probabilities were applied to this distribution to arrive at an estimated distribution of bequests by age, sex, and marital status. An additional adjustment to these figures was made in order to reconcile the U.S. aggregate net worth value estimated from the Federal Reserve tape with the FRBMIT net worth data.

Unpublished data collected by Paul Menchik and Martin David from the Washington, D.C., Inheritance Tax File for the year 1967 reveal that males who were married at the time of their death left 10 percent of their estate to their children. Married female decedents left 19 percent of their estates to their children. The proportion left to grandchildren and other young relatives is unclear, but it probably does not exceed 2 percent for males and 4 percent for females, which represents half of the percentage contribution to other relatives. For single male decedents, 32 percent of the estate is left to children; the single female proportion is 37 percent. Again taking half of the contributions to other relatives as "distant in age" intergenerational transfers, another 22 percent can be ascribed to single males and 23 percent to single females. Using these figures and the Federal Reserve simulated bequest distributions, the estimated "distant in age" intergenerational bequest transfer flow in 1962 was $\$ 11.9$ billion. Multiplying this figure by the 221.6 percent growth in the nominal value of total U.S. net worth between 1962 and 1974 gives us an estimate of the 1974 bequest transfer flow of $\$ 26.4$ billion.

In 1974 the total value of life insurance death benefits equaled $\$ 8.885$ billion. In conjunction with the Menchik numbers, this raises the $\$ 26.4$ billion bequest flow figure to $\$ 28.9$ billion.

We also estimate the flow of intergenerational transfers from parents to children that occur in the form of financial support during college. In 1974 college enrollment totaled 8.8 million students (U.S. 
Department of Commerce 1978, p. 138). In 1976 parental contributions to college-enrolled children who were taken as tax deductions averaged $\$ 1,738$ (Froomkin 1977, p. 479). Assuming that non-tax dependent college-enrolled children received one-quarter of this level of support, average support from parents in 1976 was $\$ 1,270$. Reducing this number by 15 percent, the growth in tuition between 1974 and 1976 (U.S. Department of Commerce 1978, p. 165) suggests a level of college support payments of about $\$ 1,080$ in 1974 . This type of intergenerational transfer could then account for $\$ 10.3$ billion of the total 1974 flow. Adding the 10.3 to the 28.9 leaves us with $\$ 39.2$ billion of explained transfer flows.

Another component of the intergenerational transfer flow is transfers made in the form of trusts. While direct data on the value of new trusts formed in 1974 are not available, there are fiduciary income tax data for the years 1965 and 1970 that permit a rough calculation of this transfer flow component (U.S. Internal Revenue Service 1970, p. 46). Between 1965 and 1970 the number of new trusts established each year averaged 35,098 . The 1970 income of the 152,398 existing trusts in 1970 totaled $\$ 7,513$ billion. The average 1970 trust had, therefore, an income of $\$ 9,985$. Dividing this value by our 1970 series 1 interest rate of 0.0787 gives an estimate of the average value of a 1970 trust of $\$ 126,874$. Multiplying this figure by 35,098 leads to an estimate of $\$ 4.44$ billion as the value of new trusts established in 1974 . After multiplying this number by 1.395 to allow for the growth in total wealth between 1970 and 1974, our estimate of the 1974 flow of intergenerational transfers in the form of trusts is $\$ 6.19$ billion. This figure raises the explained transfer flow to $\$ 45.4$ billion.

This $\$ 45.4$ billion figure seems small compared with the $\$ 70$ billion total flow needed if the stock of transfer wealth is $\$ 3.151$ trillion and the age gap factor is 45 . On the other hand, it is not too far from the $\$ 46$ billion total flow needed if $r$ exceeds $n$ by 2 percent and the age gap factor is 68 .

Unfortunately, before one can precisely determine the total intergenerational flow, substantially more information will have to be collected about family gift giving and support payments to children and grandchildren. These data may prove particularly difficult to obtain since we would have to estimate the value of the cedar chest passed from grandmother to grandnephew, or the family car given to son John as a college graduation present, or the value to son Alex of making him a full partner in a lucrative family business. Since the distribution of wealth is very highly skewed, such surveys need to be aimed at the intergenerational transfer payments of the very wealthy. However, the very wealthy may be the least willing to disclose these types of transfers because of potential estate and gift tax liabilities. 


\section{Summary and Conclusions}

The evidence presented in this paper rules out life-cycle hump saving as the major determinant of capital accumulation in the U.S. economy. Longitudinal age-earnings and age-consumption profiles do not exhibit the kinds of shapes needed to generate a large amount of life-cycle wealth accumulation. The view of U.S. capital formation as arising, in the main, from essentially homogeneous individuals or married spouses saving when young for their retirement is factually incorrect.

Intergenerational transfers appear to be the major element determining wealth accumulation in the United States. Our best estimates of the 1974 stock of transfer wealth after allowing for interspousal life-cycle accumulation is approximately $\$ 3$ trillion.

While these estimates of the stock of transfer wealth are quite large, totally eliminating transfers in the U.S. economy would not necessarily reduce total U.S. wealth by the full amount of transfer wealth. We have demonstrated within the context of a steady-state growth model that a $\$ 1.00$ reduction in the stock of transfer wealth may reduce total wealth by less than $\$ 1.00$ if the steady-state real interest rate exceeds the steady-state growth rate. Taking the U.S. historical real interest and growth rates as illustrative, eliminating a $\$ 3$ trillion stock of transfer wealth would reduce total U.S. wealth by about $\$ 2.1$ trillion in a steady-state context. This, however, is a partial equilibrium analysis. Substantially more research must be undertaken before we can begin to attach probable numbers to full general equilibrium responses to changes in transfers.

This paper suggests the importance of and need for substantially more research and data collection on intergenerational transfers. Economic models of savings that stress the homogeneity of agents and the importance of the demographic structure should give way to models that emphasize the rather massive intergenerational transfers in the U.S. economy and the apparent concentration of these transfers among the very wealthy.

\section{References}

Ando, Albert, and Modigliani, Franco. "The 'Life Cycle' Hypothesis of Saving: Aggregate Implications and Tests.” A.E.R. 53 (March 1963): 55-84.

$\rightarrow$ Atkinson, A. B. "The Distribution of Wealth and the Individual Life-Cycle." Oxford Econ. Papers, n.s. 23 (July 1971): 239-54.

$\rightarrow$ Barro, Robert J. "Are Government Bonds Net Wealth?" J.P.E. 82, no. 6 (November/December 1974): 1095-1117.

Boskin, Michael J. "Is Heavy Taxation of Capital Socially Desirable?" Hearings before the Subcommittee on Economic Growth and Stabilization, the Joint Economic Committee, Congress of the United States, Ninety-fifth Congress, July 1977. Washington: Government Printing Office, 1978. 
Brittain, John A. Inheritance and the Inequality of Material Wealth. Washington: Brookings Inst., 1978.

$\rightarrow$ Calvo, Guillermo A.; Kotlikoff, Laurence J.; and Rodríguez, Carlos Alfredo. "The Incidence of a Tax on Pure Rent: A New (?) Reason for an Old Answer." J.P.E. 87, no. 4 (August 1979): 869-74.

Christensen, Laurits R. "Entrepreneurial Income: How Does It Measure Up?” A.E.R. 61 (September 1971): 575-85.

Christensen, Laurits R., and Jorgenson, Dale W. U.S. Income, Saving, and Wealth, 1929-1969. Madison: Univ. Wisconsin, 1973.

Darby, Michael R. Effects of Social Security on Income and the Capital Stock. Washington: American Enterprise, 1979.

Diamond, Peter A. "Incidence of an Interest Income Tax." J. Econ. Theory 2 (September 1970): 211-24.

$\rightarrow$ Feldstein, Martin S. "Social Security, Induced Retirement, and Aggregate Capital Accumulation." J.P.E. 82, no. 5 (September/October 1974): 905-26.

Froomkin, Joseph. Tax Treatment of Tuition Expenses. Testimony to the Committee on Ways and Means, Hearings before the Committee on Ways and Means, House of Representatives, Ninety-fifth Congress, Serial 95-56. Washington: Government Printing Office, 1977.

Goldsmith, Raymond W., and Lipsey, Robert E. Studies in the National Balance Sheet of the United States. Vol. 1. Princeton, N.J.: Princeton Univ. Press (for Nat. Bur. Econ. Res.), 1963.

$\rightarrow$ Kotlikoff, Laurence J. "Social Security and Equilibrium Capital Intensity." Q.J.E. 93 (May 1979): 233-53.

$\rightarrow$ Kotlikoff, Laurence J., and Summers, Lawrence H. "Tax Incidence in a Life Cycle Model with Variable Labor Supply." Q.J.E. 93 (November 1979): 705-18.

- "The Role of Intergenerational Transfers in Aggregate Capital Accumulation." Working Paper no. 445, Nat. Bur. Econ. Res., February 1980.

Kuznets, Simon S. National Income and Its Composition, 1919-1938, I and II. New York: Nat. Bur. Econ. Res., 1941.

- National Product since 1869. New York: Arno (for Nat. Bur. Econ. Res.), 1946.

Leven, Maurice; Moulton, Harold G.; and Warburton, Clark. America's Capacity to Consume. Washington: Brookings, 1934.

Mirer, Thad W. "The Wealth-Age Relation among the Aged." A.E.R. 69 (June 1979): 435-43.

Modigliani, Franco, and Brumberg, Richard. "Utility Analysis and the Consumption Function: An Interpretation of Cross-Section Data." In PostKeynesian Economics, edited by Kenneth K. Kurihara. New Brunswick, N.J.: Rutgers Univ. Press, 1954.

$\rightarrow$ Oulton, Nicholas. "Inheritance and the Distribution of Wealth." Oxford Econ. Papers, n.s. 28 (March 1976): 86-101.

Tobin, James. "Life Cycle Saving and Balanced Growth." In Ten Economic Studies in the Tradition of Irving Fisher, edited by William Fellner et al. New York: Wiley, 1967.

Tobin, James, and Dalde, Walter. "Wealth, Liquidity, and Consumption." In Consumer Spending and Monetary Policy: The Linkages. Federal Reserve Bank of Boston Monetary Conference, vol. 5. Boston: Federal Reserve Bank of Boston, 1971.

U.S. Department of Commerce, Bureau of the Census. Historical Statistics of the U.S., Colonial Times to 1970. Washington: Government Printing Office, 1975. 

1978.

U.S. Statistical Abstract. Washington: Government Printing Office,

U.S. Department of Commerce, Bureau of Economic Analysis. Long Term Economic Growth, 1860-1970. Washington: Government Printing Office, 1973.

- The National Income and Product Accounts of the United States, 19291974, Statistical Tables. Washington: Government Printing Office, 1976.

U.S. Department of Labor, Bureau of Labor Statistics. Employment and Training Report of the President. Washington: Government Printing Office, 1978.

U.S. Internal Revenue Service. Statistics of Income. Washington: Government Printing Office, 1970.

U.S. Securities and Exchange Commission. Statistical Bulletin. Washington: Government Printing Office, 1977.

von Furstenberg, George M. "Corporate Investment: Does Market Valuation Matter in the Aggregate?" Brookings Papers Econ. Activity, no. 2 (1977), pp. 347-97.

White, Betsy Buttrill. "Empirical Tests of the Life-Cycle Hypothesis." A.E.R. 68 (September 1978): 547-60. 